\title{
The assessment of detachment among university students: Validation of the Recovery Experience Questionnaire in educational contexts
}

\author{
Enrique Merino-Tejedor ${ }^{*}$, Pedro M. Hontangas ${ }^{2}$, and Joan Boada-Grau ${ }^{3}$ \\ ${ }^{1}$ University of V alladolid, Department of Psychology, Faculty of Education at Segovia (Spain) \\ ${ }^{2}$ University of V alencia, Department of Methodology of Behavioral Sciences (Spain) \\ ${ }^{3}$ Rovira i Virgili University, Department of Psychology (Spain)
}

Título: La evaluación del distanciamiento psicológico (detachment) en estudiantes universitarios: Validación del Cuestionario de Experiencia de Recuperación en contextos educativos.

Resumen: El objetivo de este estudio fue adaptar y validar el Cuestionario de Experiencias de Recuperación (Recovery Experience Questionnaire) para su uso en un contexto educativo. Hasta el momento, la evaluación del detachment o distanciamiento psicológico ha sido utilizada fundamentalmente en contextos laborales. El estudio tuvo como objetivo verificar la validez factorial y la validez de criterio, a través de la correlación con variables como la autorregulación, el compromiso (engagement), las estrategias de afrontamiento, y las dimensiones de la personalidad contempladas en el modelo de los cinco grandes factores (Big Five Model) en una muestra de 468 estudiantes universitarios españoles. Varios modelos propuestos en la literatura han sido probados a través del análisis factorial confirmatorio. Los resultados obtenidos confirmaron la presencia de los cuatro factores siguientes: el distanciamiento psicológico, la relajación, el dominio, y el control. Estos son los mismos factores que se han observado en estudios previos dentro de los entornos laborales. Las correlaciones obtenidas entre estos cuatro factores y las variables consideradas verifican que el detachment está asociado de forma positiva y significativa con la autorregulación, el compromiso, las estrategias de afrontamiento, y ciertas dimensiones de personalidad. Por otro lado, el detachment mostró una relación significativa y negativa con variables de tipo negativo como la irritación.

Palabras clave: Distanciamiento psicológico; compromiso; irritación; autorregulación.

\section{Introduction}

Detachment is a construct which has largely been studied in the context of the workplace in which it is associated with experiences of recovery at the end of the working day. In recent years, the number of studies on recovery experience has increased (Bakker, Demerouti, Oerlemans, \& Sonnentag, 2013; Fritz, Yankelevich, Zarubin, \& Barger, 2010), manifesting the importance of this construct in the field of psychological assessment and research.

Sonnentag and Bayer (2005) introduced the term psychological detachment in their research into stress and stress recovery. It is related to the personal capacity to disconnect psychologically when away from the workplace. This capacity has two important features: not to carry out work-related tasks, and not to dwell on work-related matters (Sonnentag \& Fritz, 2014). Important in this line of research are the contributions of Sonnentag on the role of detachment in wellbeing in the workplace, mainly with the development of the

* Correspondence address [Dirección para correspondencia]:

Enrique Merino-Tejedor. University of Valladolid, Department of Psychology, Faculty of Education at Segovia, Campus María Zambrano, Plaza de la Universidad, 1, 40.005 Segovia (Spain).

E-mail: enrique.merino@uva.es
Abstract: The objective of this study was to adapt and validate the Recovery Experience Questionnaire for use in an educational context. So far, this measure of detachment has mainly been used with workers. The study aimed to verify the factor validity and the criterion-related validity through correlation with self-regulation, engagement, coping strategies, and big-five personality dimensions in a sample of 468 Spanish university students. Several models proposed in the literature have been tested through confirmatory factor analysis. The results obtained confirmed the presence of four factors: psychological detachment, relaxation, mastery and control, as observed in previous studies within a workplace setting. Correlations obtained between these factors and the variables considered verified that detachment is significantly and positively associated with self-regulation, engagement, coping strategies, and certain types of personality; on the other side, detachment is significantly and negatively associated with irritation. Key words: Detachment; Engagement; Irritation; Self-regulation. theoretical model known as the "stressor-detachment model" (Sonnentag, 2010).

A lack of detachment is directly linked to having recurring thoughts such as rumination, a concept related to the tendency to recurrently dwell upon the same thoughts away from the environment in which they are appropriate (Martin $\&$ Tesser, 1996). Although the concepts of lack of detachment and rumination share elements in common, they are not strictly the same (Sonnetag \& Fritz, 2014).

Sonnentag and Fritz (2007) designed the Recovery Experience Questionnaire to evaluate this construct; the final version is composed of 16 items and 4 dimensions: Psychological detachment, relaxation, mastery, and control. The theoretical model of detachment assumes that coping styles are related to recovery experiences; however, although some correlations were found for social support or active coping, empirical research found low and mostly non-significant correlations between most coping measures and recovery experiences. Low and non-significant correlations have also been found for personality traits, indicating that personality is not a good predictor of recovery experiences, with the exception of openness to experience and extraversion which are related to mastery, and emotional stability which is related to psychological detachment, mastery, and control (Sonnentag \& Fritz, 2007). Of the results found to be significant, it is worth noting the relationship between openness to experi- 
ence and extraversion with mastery and, on the other hand, emotional stability which has shown positive correlations with psychological detachment, mastery, and control.

Current research has shown the convenience of the validation of recovery experiences scores among students. For example, Ragsdale et al., (2011) have already developed an integrative model of recovery among undergraduate students. They include in their model not only recovery experiences, but also recovery quality, need for recovery, and recovery activities (resource-providing and resourceconsuming activities). They affirm that "students need to take action and participate in resource-providing recovery activities during leisure time to bring about the recovery experiences and subsequent reduced need for recovery and reduced strains" (Ragsdale et al., 2011, p. 171). On the other hand, Schraub, Turgut, Clavairoly, and Sonntag (2013) have also explored recovery experiences and well-being among students.

In relation to the additional variables selected for this study, we present the following reasons that justify their presence in a research on detachment among college students.

Self-regulation is an ability whose adaptive value has been shown in different contexts, such as well-being (Baumann, Kaschel, \& Kuhl, 2005), or health promotion (Fuhrman \& Kuhl, 1998), so it seems important to test its relation to detachment. Another variable included is irritation, which has been considered a kind of academic stress related to health dimensions among university students (MerinoTejedor, Boada-Grau, Sánchez-García, \& HontangasBeltrán, 2013), so it seems also relevant to investigate its relation to detachment.

On the other hand, personality and coping have been considered as potential predictors of recovery experiences from a theoretical point of view (Sonnentag \& Fritz, 2007). In the case of correlations between personality and measures of recovery experiences, although according to authors results were low, it seems appropriate to test whether the same findings can be found in the case of college students. The same reasoning can be applied in the case of coping measures, which previous research has found low correlations, but for example in the case of "problem-focused coping was related to the recovery experience control which might reflect a person's overall tendency to actively approach everyday situations and problems" (Sonnentag \& Fritz, 2007, p. 216). These findings encourage the possibility to go on with further research on coping strategies and detachment. In addition, a study found evidence of a relationship between detachment and coping in undergraduate students (Lawrence, Ashford, \& Den, 2006; Roger, Jarvis, \& Najarian, 1993). Another study on the validation of a scale of coping included a scale called detachment (Roger, Jarvis, \& Najarian, 1993).

Finally, regarding the incorporation of the variable engagement, a current investigation carried out by Shimazu, Matsudaira, De Jonge, Tosaka, Watanabe, and Takahashi
(2016) indicates that detachment has a curvilinear relationship with the engagement in a sample of Japanese workers. Although the detachment can improve mental health of employees, moderate levels of detachment are most beneficial for appropriate engagement. Another study shows that not only the detachment during leisure time, but also the detachment when returning to work turns out to be crucial for engagement in a sample of employees (Sonnentag \& Kühnel, 2016). Therefore, it seems appropriate to test in which degree a higher level of academic engagement affects recovery experiences among college students.

The Recovery Experience Questionnaire was adapted into Spanish by Sanz-Vergel et al. (2010) with a sample of workers in the security sector. They favoured a reduced version containing 12 items with the same four-dimensional factorial structure and satisfactory reliability coefficients, as will be outlined in the description of research instruments. Despite the importance that detachment is gaining in the workplace, currently, some authors have addressed the study of detachment among university students (Larson, 2006; Misra \& Castillo, 2004; Ragsdale, Beehr, Grebner, \& Han, 2011). It is important to highlight that students have greater difficulty in disconnecting from their work, due to the time they must dedicate to study outside the classroom.

The main purpose of this research is to assess whether detachment, assessed through the Recovery Experience Questionnaire, may be applied in other contexts, such as with university students, testing for generalizability with Messick's (1995) model.

Some scales have also been adapted to different environments. For example, this is the case of the MBI- General Survey (Salanova, Grau, Llorens, \& Schaufeli, 2001) that led to the MBI-Student Survey (Schaufeli, Martínez, MarquésPinto, Salanova, \& Bakker, 2002). Also, the School-Burnout Inventory (SBI, Salmela-Aro, Kiuru, Leskinen, \& Nurmi, 2009) has been adapted to different student populations.

The initial hypothesis, following on from previous research, is that the Confirmatory Factor Analysis (CFA) will verify the existence four independent factors: Psychological detachment, relaxation, mastery, and control. The second aim is to determine the external validity of the questionnaire, comparing the results with those obtained with other variables such as self-regulation, engagement, coping strategies, personality traits, and irritation.

To sum up, the objective of this study was to adapt the Recovery Experience Questionnaire for use in an educational context, addressing three of the six aspects of Messick's framework (1995) on construct validity: structural (factorial structure analyzed via CFA), external (relationships with other psychological constructs), and generalizability (conducting the questionnaire on a university sample, which is a novel and different application). 


\section{Method}

\section{Procedure and Participants}

Data collection was undertaken during the 2013-2014 academic year. The study was conducted via online survey. The sample used in the study consisted of 468 Spanish university students. Subjects were not randomly chosen, and they participated in the process of data collection on a strictly voluntary basis and were informed of the aims of the study. In terms of gender distribution, there were 182 males $(38.9 \%)$, and 286 females $(61.1 \%)$, reflecting the current gender ratio in Spanish universities. The average age of participants was $20.9(S D=6.00)$. In terms of the level of study, 430 participants $(91.9 \%)$ were degree students, 4 $(0.9 \%)$, were studying for a diploma, $22(4.7 \%)$, were studying towards a licentiate, and 12 (2.6\%), other types of study, such as a Master's degree. In terms of the year of study, 288 of the subjects $(61.5 \%)$ were in their first year, $95(20.3 \%)$ in their second year, $34(7.3 \%)$ in their third year, $34(7.3 \%)$ in their fourth year, $15(3.2 \%)$ in their fifth year and, finally, 2 students $(0.4 \%)$ were in their sixth year.

\section{Research instruments}

Before responding to the research instruments, subjects were required to answer a number of questions regarding important data from their academic and personal life, such as their marks in the previous academic year, their perception of their teachers' and peers' support, and their level of satisfaction with their studies. Specifically, participants were asked to respond to the following questions in a Likert type scale ranging from 1 (minimum) to 10 (maximum): "What was your average mark during the last academic year?", "How do you value your teachers' support?", "How do you value your peers' support"? "How satisfied are you with your current studies?"

The following research instruments were used:

The Recovery Experience Questionnaire- This instrument was originally designed by Sonnentag \& Fritz (2007). The Spanish version was adapted for the context of the workplace by Sanz-Vergel et al., (2010). The content of the items has been modified for university students. This adaptation consists of 16 items gathered in four factors: Psychological detachment ("I am able to disconnect after class"), relaxation, ("I engage in activities which help me to feel relaxed"), mastery, ("I look for new intellectual challenges outside university) and control, ("Outside class, I can manage my own timetable"). These factors are defined by different items in both studies (see Methods section). Internal consistency values show adequate reliability ratings in the four factors: Cronbach's alpha's of .87 in the case of psychological detachment; .75 for relaxation; .85 for mastery; and .88 for control. Items are an- swered through a Likert-type scale ranging from 1 (completely disagree) to 5 (completely agree).

The Irritation Scale- The Irritation Scale is currently published and commercialized by the German group Hogrefe Publishing Company. This 8-item scale was initially created by Mohr (1986), and it has been developed through international research (Mohr, Müller, Rigotti, Aycan, \& Tschan, 2006). Results would seem to confirm a two-dimensional structure, with one component known as cognitive irritation, and another known as emotional irritation. Although the scale was initially created for the assessment of work strain, it has already been used in Spanish with university students (MerinoTejedor et al., 2013) adapting the items to the academic context, both for cognitive irritation ("I have difficulty relaxing after attending class"), and for emotional irritation ("I get angry quickly"). Consistent results have been obtained in reliability (Cronbach's alpha .79 for emotional irritation, and .83 for cognitive irritation). The 8 items of the scale are answered through a Likert-type scale ranging from 1 (completely disagree) to 7 (completely agree).

The Self-Regulation Scale.- The third instrument used in this study is the Self-Regulation Scale (Luszczynska, Diehl, Gutiérrez-Doña, Kuusinen, \& Schwarzer, 2004), specifically the most recent version reduced to 7 items (e.g., "I stay focused on my goal and don't allow anything to distract me from my plan of action"). The internal consistency values of the scale vary between Cronbach's alpha values of .63 and .87. In terms of validity, significant values have been found with perceived general self-efficacy $(r=.75, p<.001)$ or depression $(r=-.25, p<.001)$ (Luszczynska et al., 2004). The scale is answered through a Likert-type scale ranging from 1 (not al all) to 4 (a lot).

Engagement.- In order to evaluate engagement, derivation of the Utrecht Work Engagement Scale (UWES) was used, an instrument which has undergone several adaptations into Spanish by the Salanova team. In the present study the 24item version was used (Schaufeli, Salanova, González-Romá, \& Bakker, 2002) with the following dimensions: Dedication (8 items, e.g. "I feel fulfilled by my studies"); absorption (7 items, e.g. "I am happy when doing work related to my studies"); vigour (9 items, e.g. "When I get up in the morning I am in the mood for going to class or studying"). In student samples data with acceptable levels of reliability have been obtained (Cronbach's alpha of .78 for vigour, .84 for dedication, and .73 for absorption). Items are answered through a Likert-type scale ranging from 1 (never) to 5 (always).

Brief COPE.- The COPE is an instrument used in a number of studies to evaluate coping strategies, including research with a Spanish version (Perczek, Carver, \& Price, 2000). In the present study the Brief COPE version was used (Carver, 1997) which evaluates 12 coping strategies: self-distraction; active coping; denial; substance use; use of emotional sup- 
port; behavioural disengagement; venting; positive reframing; planning; humour; acceptance; and religion. The internal consistency values of the scale vary between Cronbach's alpha's values of .50 for venting, and .90 for substance use.

Sonnentag and Fritz (2007) used a version of the instrument designed by Carver, Scheier, \& Weintraub (1989) with the following dimensions: problem-focused coping (active coping, planning, restraint coping, use of instrumental social support); emotion-focused coping (denial, use of emotional social support); and other (focus on emotions, behavioural disengagement, and mental disengagement). The present research employed dimensions coinciding with those of Sonnentag and Fritz (2007): Active coping, planning, emotional support, denial, behavioural disengagement; and others which did not coincide: Self-distraction, venting, positive reframing, and acceptance.

Overall Personality Assessment Scale.- This questionnaire developed by Vigil-Colet, Morales-Vives, Camps, Tous, \& Lorenzo-Seva (2011) is based on the model considering the big five factors of personality: extraversion, emotional stability, agreeableness, conscientiousness and openness to experience (Costa \& McCrae, 1992). It must be taken into account that, in this case, emotional stability was assessed instead of neuroticism. The questionnaire consists of a total of 40 items (e.g., "I feel comfortable with myself"). In relation to the psychometric factors, the results found show an adequate goodness-of-fit to the Five Factor Model. The reliability values of the factors obtained in previous studies through Cronbach's alpha coefficient (Vigil-Colet al., 2011) are as follows: .86 for extraversion and emotional stability, .77 for conscientiousness, .71 for agreeableness and .81 for openness to experience. Items are assessed on a Likert-type scale with options ranging from 1 (completely disagree) to 5 (completely agree).

\section{Statistical Analyses}

Tested model. From the work of Sonnentag \& Fritz (2007) and Sanz et al. (2010), the model with the better fit was selected. This model was the reduced version of The Recovery Experience Questionnaire composed by 12 items and 4 dimensions (psychological detachment, relaxation, mastery, and control). On the other hand, the dimensional structure of the Brief COPE Questionnaire was also tested, using nine coping strategies composed by two item each one (selfdistraction, active coping, denial, emotional support, behavioural disengagement, venting, positive reframing, planning, and acceptance).

Confirmatory factor analysis (CFA). The analyses are carried out using the EQS 6.1 software package, using the method of maximum likelihood with robust estimation by Satorra-Bentler (Bentler, 1995, 2005), following the recommendations of Finney and DiStefano (2006) and Byrne (2006), given that the multivariate normal distribution is not sufficient (Mardia's multivariate coefficient for The Recovery Experience Questionnaire and Brief COPE Questionnaire are 34.23 and 21.07). The adjustment is evaluated using indices based on different estimations (Hu \& Bentler, 1999; Marsh, Balla, $\&$ Hau, 1996): $\chi^{2}$ (statistical chi-squared), NNFI (Nonnormed fit index, or TLI, Tuker-Lewis index), CFI (Comparative fit index), and RMSEA (Root mean square error of approximation). A $\chi^{2}$ value with a probability greater than .05 indicates good fit; however, this statistic is affected by several limitations and, therefore, other indices are used (NNFI, CFI and RMSEA) which are less influenced by the sample size and the complexity of the model (Bollen \& Long, 1993). On the NNFI and CFI indices, values above .90 indicate a reasonable fit, although values greater than .95 are desirable. Although a RMSEA value lower than .07 can be considered a reasonable fit (Steiger, 2007), values lower than .05 are preferable ( $\mathrm{Hu} \&$ Bentler, 1999). It has also been suggested that the combination of a CFI greater than .90 and a RMSEA lower than .06 can indicate a good fit (Hu \& Bentler, 1999).

Reliability was obtained through Cronbach's alpha value, while Pearson's correlation coefficient was used for the analysis of external validity. Stepwise multiple regression analyses were also performed. These analyses were carried out using the statistical package SPSS 19.0.

\section{Results}

\section{Factorial validity}

The results corresponding to the goodness-of-fit indices are shown in Table 1. The four factors model of The Recovery Experience Questionnaire presents a good fit (NNFI $=.918$, $\mathrm{CFI}=.940$, RMSEA $=.062$ ). The factorial saturations and the correlations between the factors are shown in Figure 1. The saturations of the items in their respective factors are high, between .66 and .88 , and the correlations between the factors are positive and statistically significant, except in the cases of psychological detachment and mastery, which are independent. Therefore, the results support the structure of four factors obtained by Sonnentag \& Fritz (2007) and Sanz et al. (2010) in a work context, and indicate that the reduced 12 -item version has the same dimensions in an academic context.

On the other hand, the results of confirmatory factor analysis by the nine coping strategies of Brief COPE Questionnaire have also shown a very good fit $(\mathrm{NNFI}=.943$, CFI $=$ .963 , RMSEA $=.035)$. The range of factorial saturations is from .44 to .85 and all correlations between the factors are positive and statistically significant, except three cases are independent (denial and active coping, denial and positive reframing, behavioral disengagement), and three correlations are negatives (behavioral disengagement with active coping, planning and acceptance). 
Table 1. Goodness-of-fit indices for the models

\begin{tabular}{|c|c|c|c|c|c|}
\hline Models & $\mathrm{SB} \chi^{2}$ & $\mathrm{df}$ & NNFI & CFI & RMSEA \\
\hline REQ & $135.44 * *$ & 48 & .918 & .940 & .062 \\
\hline Brief COPE & $156.07 * *$ & 90 & .943 & .963 & .035 \\
\hline
\end{tabular}

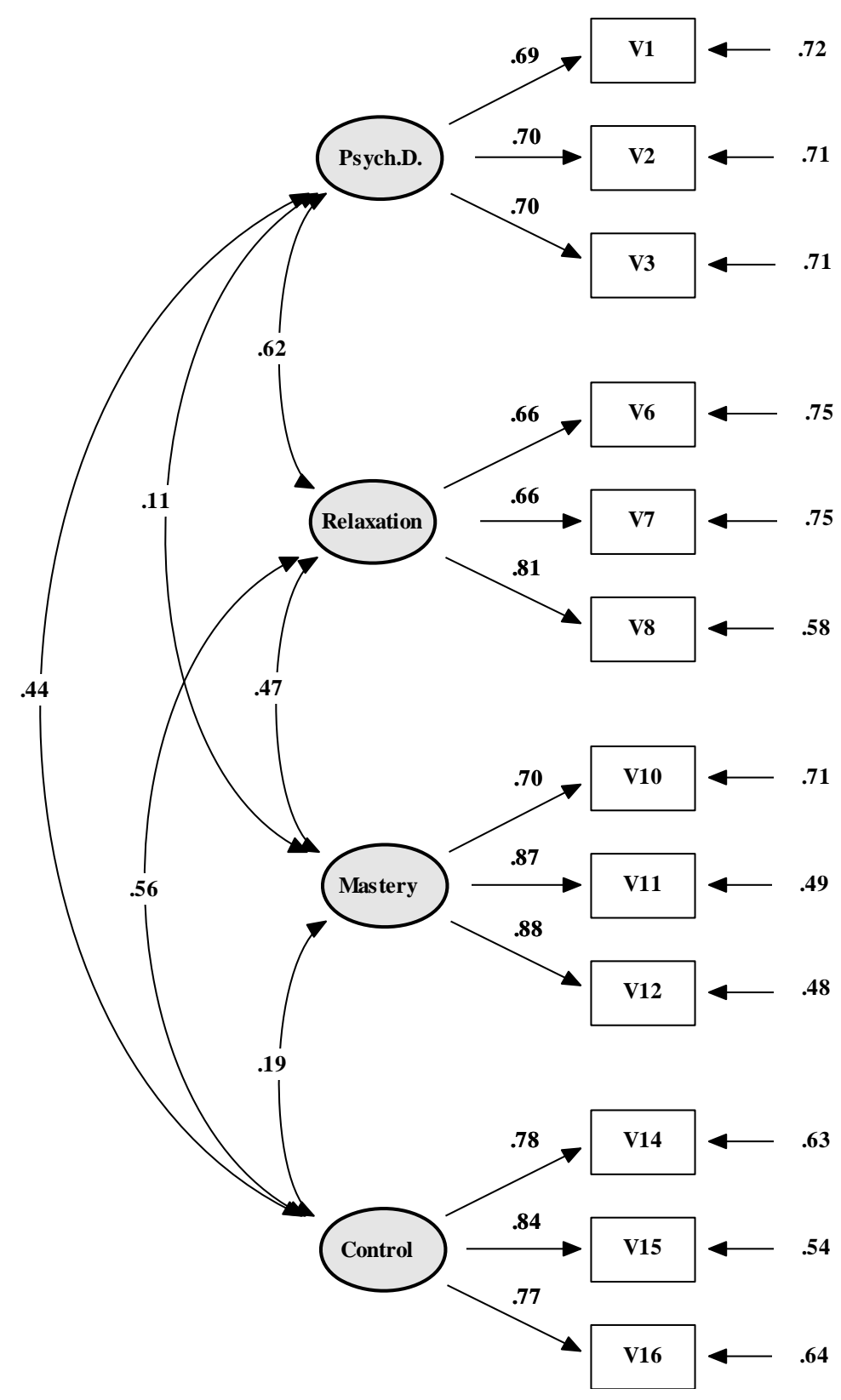

Figure 1. Factor loadings and correlations of four-factor model. 


\section{Reliability Analysis}

Internal consistency coefficients (Cronbach's alpha) of the Recovery Experience Questionnaire and other variables, as well as measures of central tendency and dispersion, are shown in Table 2. The mean obtained from global detachment reached a value of $43.75(S D=7.86)$, and the averages for the four dimensions were: psychological detachment $10.13(S D=2.61)$; relaxation $11.53(S D=2.70)$; mastery
$9.93(S D=3.19)$; and control 12.17 (SD = 2.84). Reliability analysis yielded an internal consistency coefficient of .83 for the global questionnaire. In terms of the four factors of the detachment questionnaire, both psychological detachment and relaxation scored a Cronbach's alpha of .74, while the result for the factor corresponding to mastery was .86 , with a similar figure (.84) for the factor of control. The reliability of the other variables is satisfactory with values between .80 and .93 (see Table 2).

Table 2. Descriptive statistics and reliability

\begin{tabular}{|c|c|c|c|c|c|}
\hline Variable & Minimum & Maximum & Mean & $S D$ & Cronbach's alpha \\
\hline Global Detachment & 12 & 60 & 43.75 & 7.86 & .83 \\
\hline Psychol. detachment & 3 & 15 & 10.13 & 2.61 & .74 \\
\hline Relaxation & 3 & 15 & 11.53 & 2.70 & .74 \\
\hline Mastery & 3 & 15 & 9.93 & 3.19 & .86 \\
\hline Control & 3 & 15 & 12.17 & 2.84 & .84 \\
\hline Self-regulation & 7 & 28 & 19.09 & 3.64 & .80 \\
\hline Global Irritation & 8 & 54 & 21.07 & 8.72 & .84 \\
\hline Cognitive Irritation & 3 & 21 & 7.35 & 3.81 & .78 \\
\hline Emotional Irritation & 5 & 35 & 13.72 & 6.24 & .82 \\
\hline Engagement & 24 & 159 & 111.51 & 22.45 & .93 \\
\hline Dedication & 8 & 56 & 44.17 & 9.30 & .92 \\
\hline Absorption & 7 & 47 & 29.77 & 7.45 & .83 \\
\hline Vigor & 9 & 57 & 37.56 & 8.41 & .83 \\
\hline
\end{tabular}

\section{Bivariate correlation analysis}

In order to analyse these results, the correlations obtained between the Recovery Experience Questionnaire and the other variables considered in this study will be analysed be- low. The results obtained from this analysis are displayed in Table 3. As shown in this table, the Pearson correlation coefficients indicate that all variables displayed significant correlations in the manner expected, lending support to the external aspect of construct validity (Messick, 1995).

Table 3. Correlations between the variables and detachment.

\begin{tabular}{|c|c|c|c|c|c|}
\hline Variable & Psychological Detachment & Relaxation & Mastery & Control & Global Detachment \\
\hline Global Irritation & $-.31 * *$ & $-.17^{* *}$ & .03 & -.01 & $-.15^{* *}$ \\
\hline Cognitive Irritation & $-.46^{* *}$ & $-.21 * *$ & $.10^{*}$ & -.04 & $-.20 * *$ \\
\hline Emotional Irritation & $-.15^{* *}$ & $-.11 *$ & -.03 & .02 & $-.09 *$ \\
\hline Self-Regulation & $.19^{* *}$ & $.29 * *$ & $.28^{* *}$ & $.27^{* *}$ & $.37 * *$ \\
\hline Engagement & -.01 & $.27^{* *}$ & $.38^{* *}$ & $.27 * *$ & $.34 * *$ \\
\hline Dedication & .07 & $.33^{* *}$ & $.30^{* *}$ & $.32^{* *}$ & $.37 * *$ \\
\hline Absorption & -.09 & $.15^{* *}$ & $.35^{* *}$ & $.19 * *$ & $.23 * *$ \\
\hline Vigor & -.02 & $.23^{* *}$ & $.37 * *$ & $.21 * *$ & $.30 * *$ \\
\hline \multicolumn{6}{|l|}{ Personality } \\
\hline Extraversion & .02 & $.16^{* *}$ & $.13^{* *}$ & .08 & $.14 * *$ \\
\hline Emotional Stability & $.17^{* *}$ & $.22 * *$ & .08 & $.09 *$ & $.20 * *$ \\
\hline Conscientiousness & $-.12^{*}$ & -.03 & .08 & .09 & .01 \\
\hline Agreeableness & -.04 & .09 & $.15^{* *}$ & $.16^{* *}$ & $.14^{* *}$ \\
\hline Openness & -.01 & $.15^{* *}$ & $.32 * *$ & -.01 & $.18^{* *}$ \\
\hline \multicolumn{6}{|l|}{ Cope } \\
\hline Self-Distraction & $.11^{*}$ & $.22 * *$ & $.15^{* *}$ & $.18^{* *}$ & $.24 * *$ \\
\hline Active coping & $.15^{* *}$ & $.29 * *$ & $.24 * *$ & $.31 * *$ & $.36 * *$ \\
\hline Denial & -06 & -.00 & -.02 & -.01 & -.03 \\
\hline Emotional support & $.12 * *$ & $.24 * *$ & .07 & $.22 * *$ & $.23 * *$ \\
\hline Behavioral disengagement & .01 & -.08 & -.08 & -.04 & -.07 \\
\hline Venting & $.14 * *$ & $.22 * *$ & $.11 *$ & $.21 * *$ & $.24 * *$ \\
\hline Positive reframing & $.10^{*}$ & $.32 * *$ & $.24^{* *}$ & $.17 * *$ & $.30 * *$ \\
\hline Planning & $.10^{*}$ & $.30 * *$ & $.24 * *$ & $.28^{* *}$ & $.34 * *$ \\
\hline Acceptance & $.23 * *$ & $.27^{* *}$ & $.13^{* *}$ & $.30 * *$ & $.33 * *$ \\
\hline Marks in previous academic year & .05 & $.17^{* *}$ & $.19 * *$ & $.23^{* *}$ & $.24 * *$ \\
\hline Teachers' support & .02 & $.10^{*}$ & $.13^{* *}$ & $.13^{* *}$ & $.14 * *$ \\
\hline Peers'support & $.10^{*}$ & $.14^{* *}$ & $.15^{* *}$ & $.16^{* *}$ & $.20 * *$ \\
\hline Satisfaction with studies & .05 & $.21 * *$ & $.23 * *$ & $.22 * *$ & $.26 * *$ \\
\hline
\end{tabular}

Note. ${ }^{*} p<.05,{ }^{* *} p<.01$. 
First of all, negative and significant correlations were found between global detachment and irritation. Global irritation showed a negative correlation with overall detachment $(r=-.15, p<.01)$, as well as its two components, cognitive irritation $(r=-.20, p<.01)$ and emotional irritation $(r=-.09$, $p<.05)$. The strongest correlations among the dimensions of detachment were found in psychological detachment and relaxation. Thus, these data confirm the theoretical model which predicts a negative relationship between detachment and negative constructs such as academic irritation, particularly cognitive irritation.

On the other hand, detachment showed significant, positive correlations with self-regulation $(r=.37, p<.01)$, and the state of engagement. The results obtained showed significant, positive correlations between the state of detachment and global engagement $(r=.34, p<.01)$. In addition, all the dimensions presented positive correlations between themselves, except in the case of psychological detachment, where no significant correlations were found.

Detachment also showed significant and positive correlations with extraversion $(r=.14, p<.01)$, emotional stability $(r=.20, p<.01)$, agreeableness $(r=.14, p<.01)$, and openness to experience $(r=.18, p<.01)$.

Regarding coping strategies, global detachment displayed positive and significant correlations with self-distraction $(r=$ $.24, p<.01)$, active coping $(r=.36, p<.01)$, emotional sup- port $(r=.23, p<.01)$, venting $(r=.24, p<.01)$, positive reframing $(r=.30, p<.01)$, planning $(r=.34, p<.01)$, and acceptance $(r=.33, p<.01)$. On the other hand, no correlations were found in the cases of denial or behavioural disengagement.

Finally, the relationship between detachment and four correlates was tested; the relationship was significant in the case of marks in the previous academic year $(r=.24, p<.01)$, teachers' support $(r=.14, p<.01)$, peers' support $(r=.20, p$ $<.01)$, and satisfaction with studies $(r=.26, p<.01)$.

\section{Multiple regression analysis}

Several stepwise multiple regression analyses were performed to obtain the best combination of variables to predict the dimensions of detachment, and to establish their relative importance. The entry criterion was $p=.05$, and the removal criterion was $p=.10$. No problems of multicollinearity were founded (tolerance values were always higher than $.7)$, but five influential cases were eliminated $(1.1 \%$ of sample).

It is remarkable the result found for cognitive irritation, with a negative and significant value of -.52 , which explains the strong and negative influence of cognitive irritation on psychological detachment. The rest of the results are shown in Table 4.

Table 4. Stepwise Multiple Regression Analysis.

\begin{tabular}{|c|c|c|c|c|c|}
\hline Variable & Psychological Detachment & Relaxation & Mastery & Control & Global Detachment \\
\hline \multicolumn{6}{|l|}{ Global Irritation } \\
\hline Cognitive Irritation & $-.52 * *$ & $-.30 * *$ & - & $-.19 * *$ & $-.31 * *$ \\
\hline Emotional Irritation & - & - & - & $.18^{* *}$ & - \\
\hline Self-Regulation & $.21 * *$ & $.15^{* *}$ & $.12^{* *}$ & $.17^{* *}$ & $.20^{* *}$ \\
\hline \multicolumn{6}{|l|}{ Engagement } \\
\hline Dedication & - & $.22 * *$ & - & $.18^{* *}$ & $.22 * *$ \\
\hline Absorption & - & - & - & - & - \\
\hline Vigor & - & - & $.25^{* *}$ & - & - \\
\hline \multicolumn{6}{|l|}{ Personality } \\
\hline Extraversion & - & - & - & - & - \\
\hline Emotional Stability & - & - & - & - & - \\
\hline Conscientiousness & $-.11 *$ & - & - & - & - \\
\hline Agreeableness & - & - & - & $.20 * *$ & - \\
\hline Openness & - & - & $.25^{* *}$ & $-.12 * *$ & $.08^{* *}$ \\
\hline \multicolumn{6}{|l|}{ Cope } \\
\hline Self-Distraction & - & - & - & - & - \\
\hline Active coping & - & $.09 *$ & - & $.14^{* *}$ & $.19^{* *}$ \\
\hline Denial & - & - & - & - & - \\
\hline Emotional support & $.15^{* *}$ & $.09 *$ & - & - & $.10^{*}$ \\
\hline Behavioral disengagement & - & - & - & - & - \\
\hline Venting & $.13^{* *}$ & $.12^{* *}$ & - & $.08^{*}$ & $.14^{* *}$ \\
\hline Positive reframing & - & $.15^{* *}$ & $.13^{* *}$ & - & - \\
\hline Planning & - & - & - & - & - \\
\hline Acceptance & $.17 * *$ & $.10^{*}$ & - & $.18^{* *}$ & $.16^{* *}$ \\
\hline \multicolumn{6}{|l|}{ Academic aspects } \\
\hline Marks last year & - & - & - & - & - \\
\hline 'Teachers' support & - & - & - & - & - \\
\hline Peers' support & - & - & - & - & - \\
\hline Satisfaction & - & - & - & - & - \\
\hline Adjusted R ${ }^{2}$ & $.38^{* *}$ & $.31 * *$ & $.23^{* *}$ & $.28^{* *}$ & $.39 * *$ \\
\hline
\end{tabular}

Note. The standardized coefficients of the predictors are shown. ${ }^{*} p<.05,{ }^{*} p<.01$. 


\section{Discussion}

In light of the results obtained in this study, the Recovery Experience Questionnaire offers good psychometric properties for use in the assessment of detachment among university students, a different setting to that in which it has been used until now.

All the objectives proposed in this study were confirmed. Firstly, the validation of the four aforementioned factors on the instrument, through CFA, backs up the same structure offered by the instrument when used in workplace contexts with different samples of workers (Sanz-Vergel et al., 2010; Sonnentag \& Fritz, 2007).

The internal consistency data, measured using Cronbach's alpha coefficient, are favourable, as much for the questionnaire for overall detachment as for each of its four components: Psychological detachment, relaxation, mastery, and control.

Finally, in terms of the external validity, all of the objectives have been confirmed. Thus, significant and positive correlations were obtained between the factors on the Recovery Experience Questionnaire and positive constructs such as self-regulation, engagement, and coping strategies, as predicted by the theoretical model. On the other hand, significant and negative correlations were obtained between detachment and negative variables, such as academic irritation. These results were found in the four factors of detachment.

The questionnaire also shows significant, positive links with certain personality dimensions such as extraversion, emotional stability, agreeableness, and openness, lending support to and strengthening previous open-ended results (Sonnentag \& Fritz, 2007), and paving the way for future studies to investigate further the relationship between states of detachment and variables of personality.

\section{References}

Bakker, A. B., Demerouti, E., Oerlemans, W., \& Sonnentag, S. (2013). Workaholism and daily recovery: A day reconstruction study of leisure activities. Journal of Organizational Behavior, 34, 87-107. doi: $\underline{10.1002 / j o b .1796}$

Baumann, N., Kaschel, R., \& Kuhl, J. (2005). Striving for unwanted goals: Stress-dependent discrepancies between explicit and implicit achievement motives reduce subjective well-being and increase psychosomatic symptoms. Journal of Personality and Social Psychology, 89, 781-799. doi: $\underline{10.1037 / 0022-3514.89 .5 .781}$

Bentler, P.M. (1995). EQS program manual. Encino, CA: Multivariate Software.

Bentler, P. M. (2005). EQS 6.1. for Windows. Structural equations program manual. Encino, CA: Multivariate Software, Inc.

Bollen, K. A., \& Long, J. S. (1993). Testing structural equation models. Newbury Park, CA: Sage.

Byrne, B. M. (2006). Structural equation modeling with EQS: Basic concepts, applications, and programming (2nd ed.). Mahwah, NJ: Erlbaum.

Byrne, B. M. (2008). Testing for multigroup equivalence of a measuring instrument: A walk through the process. Psicothema, 20, 872-882.
In terms of the relationship with academic performance, the results were as sound as those predicted by the theoretical model, as positive correlations have been found between marks in the previous academic year and three components of detachment: relaxation, mastery, and control.

Finally, regarding the multiple regression analysis, it is worth mentioning the strong and negative influence of cognitive irritation both on psychological detachment and on relaxation. The results found in this study convey important applications for college students in order to improve their efficient response to stressful situations, such as venting, acceptance, and emotional support seeking.

Therefore, in conclusion, it can be stated that the questionnaire, which has been proven useful in workplace environments, is also an appropriate tool for measuring levels of detachment among university students, as much for its psychometric properties of internal consistency, as for its factor and construct validity. The transcendence of this study stems from the fact that if aiding university students to achieve their goals is desirable, it may be beneficial to know beforehand their state and level of detachment, in order to tackle the demands of university tasks in an appropriate manner, and to use corresponding strategies to improve their personal well-being, for example, by practicing unwinding activities such as mindfulness.

In terms of the limitations of this study, it must be noted that, although the sample was considerably large $(N=468)$, the subjects were all from the same country. Therefore, future research could study whether the scale shows the same results with a sample of international university students.

Among future lines of research there is the possibility to carry out a comparative study with students from different universities or plans of study to identify any significant differences between them. Other lines of study may consider the relationship between detachment and the degree of commitment, or the dropout rate.

Carver, S. S. (1997). You want to measure coping but your protocol's too long: Consider the Brief COPE. International Journal of Behavioral Medicine, 4(1), 92-100.

Carver, C. S., Scheier, M. F., \& Weintraub, J. K. (1989). Assessing coping strategies: A theoretical based approach. Journal of Personality and Social Psychology, 56, 267-283.

Costa, P. T., Jr., \& McCrae, R. R. (1992). Revised NEO Personality Inventory and NEO Five-Factor Inventory professional manual. Odessa, FL: Psychological Assessment Resources.

Finney, S. J., \& DiStefano, C. (2006). Non-normal and categorical data in structural equation modeling SEM. In G. R. Hancock, \& R. O. Mueller (Eds.), Structural Equation Modeling: A second course (pp. 269-314). Greenwich, CT: Information Age Publishing.

Fritz, C., Yankelevich, M., Zarubin, A., \& Barger, P. (2010). Happy, healthy and productive: The role of detachment from work during nonwork time. Journal of Applied Psychology, 95, 977-983. doi: 10.1037/a0019462

Fuhrman, A., \& Kuhl, J. (1998). Maintaining a healthy diet: Effects of personality and self-reward versus self-punishment on commitment to and enactment of self-chosen and assigned goals. Psychology and Health, 13, 651-686. doi: 10.1080/08870449808407423 
Hu, L., \& Bentler, P. M. (1995). Evaluating model fit. In R. H. Hoyle (Ed.), Structural equation modeling: Concepts, issues and applications (pp. 76-99). Thousand Oaks, CA: Sage.

Hu, L., \& Bentler, P. M. (1999). Cut-off criteria for fit indices in covariance structure analysis: Conventional criteria versus new alternatives. Structural Equation Modeling, 6, 1-55. doi: 10.1080/10705519909540118

Larson, E. A. (2006). Stress in the live of college women: Lots to do and not much time. Journal of Adolescent Research, 21, 579-606. doi: $10.1177 / 0743558406293965$

Lawrence, J., Ashford, K., \& Den, P. (2006). Gender differences in coping strategies of undergraduate students and their impact on self-esteem and attainment. Active Learning in Higher Education, 7, 273-281. doi: $\underline{10.1177 / 1469787406069058}$

Luszczynska, A., Diehl, M., Gutiérrez-Doña, B., Kuusinen, P., \& Schwarzer, R. (2004). Measuring one component of dispositional self-regulation: Attention control in goal pursuit. Personality and Individual Differences, 37(3), 555-566. doi: 10.1016/j.paid.2003.09.026

Marsh, H. W., Balla, J. R., \& Hau, K. T. (1996). An evaluation of incremental fit indices: A clarification of mathematical and empirical properties. In G. A. Marcoulides \& R. E. Schumacker (Eds.), Advanced structural equation modeling: Issues and techniques (pp. 315-353). Mahwah, NJ: Erlbaum.

Martin, L. L., \& Tesser, A. (1996). Some ruminative thoughts. In R. S. Wyer (Ed.), Ruminative thoughts (pp. 1-47). Hillsdale, NJ: Lawrence Erlbaum.

Merino-Tejedor, E., Boada-Grau, J., Sánchez-García, J. C., \& HontangasBeltrán, P. M. (2013). The Irritation Scale as an instrument to measure stress among university students. The Spanish Journal of Psychology, 16, 110. doi: $10.1017 / \operatorname{sip} .2013 .106$

Messick, S. (1995). Validity of psychological assessment: Validation of inferences from persons' responses and performances as scientific inquiry into score meaning. American Psychologist, 50, 741-749. doi: 10.1037/0003-066X.50.9.741

Misra, R., \& Castillo, L. G. (2004). Academic stress among collage students: comparison of American International Students. International Journal of Stress Management, 11, 132-148. doi: 10.1037/1072-5245.11.2.132

Mohr, G. (1986). Die Erfassung psychischer Befindensbeeinträchtigungen bei Industriearbeitern. Europäische hochschulschriften [The assessment of mental strain of industrial workers]. Frankfurt: Lang.

Mohr, G., Müller, A., Rigotti, T., Aycan, Z., \& Tschan, F. (2006). The assessment of psychological strain in work contexts: Concerning the structural equivalency of nine language adaptations of the irritation scale. European Journal of Psychological Assessment, 22(3), 198-206. doi: 10.1027/1015-5759.22.3.198

Perczek, R., Carver, C. S., \& Price, A. A. (2000). Coping, mood, and aspects of personality in Spanish translation and evidence of convergence with English versions. Journal of Personality Assessment, 74(1), 63-87. doi: 10.1207/S15327752JPA740105

Ragsdale, J. M., Beehr, T. A., Grebner, S., \& Han, K. (2011). An integrated model of weekday stress and weekend recovery of students. International Journal of Stress Management, 18(2), 153-180. doi: 10.1037/a0023190

Roger, D., Jarvis, G., \& Najarian, B. (1993). Detachment and coping: The construction and validation of a new scale for measuring coping strategies. Personality and Individual Differences, 15, 619-626. doi:10.1016/01918869(93)90003-L

Salanova, M., Grau, R., Llorens, S., \& Schaufeli, W. B. (2001). Exposición a las tecnologías de la información, burnout y engagement: el rol modula- dor de la autoeficacia profesional [Exposure to information technology, burnout and engagement: the role of self-efficacy training]. Revista de Psicología Social Aplicada, 11, 69-90.

Salmela-Aro, K., Kiuru, N., Leskinen, E., \& Nurmi, J. E. (2009). SchoolBurnout Inventory (SBI) - Reliability and validity. European Journal of Psychological Assessment, 25, 48-57. doi: 10.1027/1015-5759.25.1.48

Sanz-Vergel, A. I., Sebastián, J., Rodríguez-Muñoz, A., Garrosa, E., MorenoJiménez, B., \& Sonnentag, S. (2010). Adaptación del "Cuestionario de Experiencias de Recuperación" a una muestra española [Adaptation of the «Recovery Experience Questionnaire» in a Spanish sample]. Psicotbema, 22(4), 990-996.

Schaufeli, W. B., Martínez, I., Marqués-Pinto, A., Salanova, M., \& Bakker, A. (2002). Burnout and engagement in university students: A crossnational study. Journal of Cross-Cultural Studies, 33, 464-481. doi: $10.1177 / 0022022102033005003$

Schaufeli, W. B., Salanova, M., González-Romá, V., \& Bakker, A. B. (2002). The measurment of engagement and burnout: A two sample confirmatory factor analytic approach. Journal of Happiness Studies, 3, 71-92. doi: 10.1023/A:1015630930326

Schraub, E. M., Turgut, S., Clavairoly, V., \& Sonntag, K. (2013). Emotion regulation as a determinant of recovery experiences and well-being: A day-level study. International Journal of Stress Management, 20(4), 309-335. doi: $10.1037 / \mathrm{a} 0034483$

Shimazu, A., Matsudaira, K., De Jonge, J., Tosaka, N., Watanabe, K., \& Takahashi, M. (2016, in press). Psychological detachment from work during nonwork time: linear or curvilinear relations with mental health and work engagement? Industrial Health. doi: 10.2486/indhealth.20150097

Sonnentag, S. (2010). Recovery from fatigue: The role of psychological detachment. In P. L. Ackerman (Ed.), Cognitive fatigue: The current status and future for research and application (pp. 253-272). Washington, CD: American Psychological Association. doi: 10.1037/12343-012

Sonnentag, S., \& Bayer, U. V. (2005). Switching off mentally: Predictors and consequences of psychological detachment from work during off-job time. Journal of Occupational Health Psychology, 10(4), 393-414. doi: 10.1037/1076-8998.10.4.393

Sonnentag, S., \& Fritz, C. (2007). The Recovery Experience Questionnaire: Development and validation of a measure for assessing recuperation and unwinding from work. Journal of Occupational Health Psychology, 12, 204-221. doi: $10.1037 / 1076-8998.12 .3 .204$

Sonnentag, S., \& Fritz, C. (2014). Recovery form job stress: The stressordetachment model as an integrative framework. Journal of Organizational Behavior, 36, 72-103. doi: 10.1002/job.1924

Sonnentag, S., \& Kühnel, J. (2016, in press). Coming back to work in the morning: Psychological detachment and reattachment as predictors of work engagement. Journal of Occupational Health Psychology. doi: $10.1037 /$ ocp 0000020

Steiger, J. H. (2007). Understanding the limitations of global fit assessment in structural equation modelling. Personality and Individual Differences, 42, 893-898. doi: 10.1016/i.paid.2006.09.017

Vigil-Colet, A., Morales-Vives, F., Camps, E., Tous, J., y Lorenzo-Seva, U. (2013). Development and validation of the Overall Personality Assessment Scale (OPERAS). Psicothema, 25(1), 100-106. doi: 10.7334/psicothema2011.411

(Article received: 07-02-2016; revised: 02-06-2016; accepted: 02-06-2016) 